\title{
Zebrafish as a model of neurodevelopmental disorders
}

Murilo S. de Abreu ${ }^{1,2 \#^{*}}$, Rafael Genario ${ }^{1 \#}$, Ana C. V.V. Giacomini ${ }^{1,3}$, Konstantin A. Demin ${ }^{4,5}$, Anton M . Lakstygal ${ }^{5,6}$, Tamara G. Amstislavskaya ${ }^{7}$, Barbara Dotto Fontana ${ }^{8}$, Matthew O. Parker ${ }^{8}$, and Allan V. Kalueff ${ }^{9,10^{*}}$

${ }^{1}$ Bioscience Institute, University of Passo Fundo (UPF), Passo Fundo, RS, Brazil

${ }^{2}$ The International Zebrafish Neuroscience Research Consortium (ZNRC), Slidell, LA, USA

${ }^{3}$ Postgraduate Program in Environmental Sciences, University of Passo Fundo, Passo Fundo, Brazil

${ }^{4}$ Institute of Experimental Medicine, Almazov National Medical Research Center, Ministry of Healthcare of Russian Federation, St. Petersburg, Russia

${ }^{5}$ Institute of Translational Biomedicine, St. Petersburg State University, St. Petersburg, Russia ${ }^{6}$ Granov Russian Scientific Research Center of Radiology and Surgical Technologies, Ministry of Healthcare of Russian Federation, Pesochny, Russia

${ }^{7}$ Research Institute of Physiology and Basic Medicine, Novosibirsk, Russia

${ }^{8}$ Brain and Behaviour Laboratory, School of Pharmacy and Biomedical Science, University of Portsmouth, Portsmouth, UK

${ }^{9}$ School of Pharmacy, Southwest University, Chongqing, China

${ }^{10}$ Ural Federal University, Ekaterinburg, Russia

\# shared first authorship

\section{*Co-corresponding authors:}

Murilo S. de Abreu, PhD, Bioscience Institute, University of Passo Fundo, Passo Fundo, Brazil. Tel: +-55-54-3316-8312, Fax:+55-54-3316-8317, E-mail: abreu_murilo@hotmail.com Allan V. Kalueff, PhD, School of Pharmacy, Southwest University, Chongqing, China.

Tel/Fax: +1-240-899-9571. E-mail: avkalueff@gmail.com 


\begin{abstract}
Neurodevelopmental disorders (NDDs) caused by aberrant brain growth and development are life-long, debilitating illnesses that markedly impair the quality of life. Animal models are a valuable tool for studying NDD pathobiology and therapies. Mounting evidence suggests the zebrafish (Danio rerio) as a useful model organism to study NDDs with high physiological homology to humans and sensitivity to pharmacological and genetic manipulations. Here, we summarize experimental models of NDDs in zebrafish and highlight the growing translational significance of zebrafish NDD-related phenotypes. We also emphasize the need in further development of zebrafish models of NDDs to improve our understanding of their pathogenesis and therapeutic treatments.
\end{abstract}

Key words: animal models; autism; attention-deficit/hyperactivity disorder; neurodevelopment; genetic models. 


\section{Introduction}

Neurodevelopmental disorders (NDDs) are life-long debilitating conditions caused by aberrant growth and development of the central nervous system (CNS) (Thapar A et al., 2017; Young S et al., 2018). Currently recognized major clinical NDDs, to be discussed here, include communication disorders, autism spectrum disorder (ASD), attention deficit/hyperactivity disorder (ADHD), intellectual disability (ID), specific learning disorder and motor/tic disorders (American Psychiatric A, 2013). For example, ASD causes robust behavioral (e.g., hyperactivity, repetitive behaviors), emotional (e.g., low affectivity/empathy) and social deficits (American Psychiatric A, 2013;Elsabbagh M et al., 2012;Lainhart JEJIRoP, 1999; Simonoff E et al., 2013). ADHD causes hyperactivity and inattention (e.g., easy distraction and impulsivity) (American Psychiatric A, 2013;Mayes SD et al., 2000;Mayes SD and Calhoun SLJCN, 2007). Global developmental delay (Moeschler JB and Shevell M, 2014) is characterized by delay in motor, speech/language, cognitive, social/personal, and activities of daily living (Shevell MI et al., 2003). Another common NDD, ID presents as reduced intellectual functioning and adaptive behavior, impaired conceptual, social and practical adaptive skills (Schalock RL et al., 2007), as well as deficits in cognitive capacities (American Psychiatric A, 2013).

The etiology of NDDs is multi-factorial, complex and poorly understood (Gathercole SE et al., 2006;Krakowiak P et al., 2012;Lewis DA and Levitt PJAron, 2002;Newcorn JH et al., 2015; Thapar A,Cooper M and Rutter MJTLP, 2017). For instance, ADHD is associated with complications at birth, as well as genetic and environmental factors (e.g., chemical exposure or drug intake during gestation) (Lou HJAP, 1996;Millichap JGJP, 2008;Nigg JTJJoCC and Psychology A, 2012; Thapar A et al., 2013). ASD is linked to metabolic pathologies during pregnancy (e.g., obesity, diabetes) and immune disorders (Currenti SAJC and neurobiology m, 2010;Krakowiak P,Walker CK,Bremer AA,Baker AS,Ozonoff S,Hansen RL and Hertz-Picciotto IJP, 2012;Pessah IN et al., 2008). Genetic factors also play a role in NDDs, for example, causing specific NDD (e.g., Down, Smith-Magenis and William's-Beuren) syndromes (Martens G and 
van Loo KJCg, 2007). However, the underlying mechanisms of NDDs remain unclear (Martens G and van Loo KJCg, 2007;Miles JHJGiM, 2011), necessitating further research in this field.

Animal models have been used to evaluate the etiology and develop new therapies for NDDs and associated comorbidities (Gatto CL and Broadie KJCoin, 2011;Kalueff AV et al., 2014;Meyer U et al., 2009; Tropepe V et al., 2003). Complementing rodent models, the zebrafish (Danio rerio) is emerging as a valuable model organism in CNS research and drug screening (Best J et al., 2008;Khan KM et al., 2017;MacRae CA and Peterson RTJNrDd, 2015;Rihel J and Schier AFJDn, 2012). Here, we summarize the mounting evidence for modeling NDDs in zebrafish, focusing on important translational lessons from using this model organism and selected NDDs chosen based on the Diagnostic and Statistical Manual of Mental Disorders (DSM-V (American Psychiatric A, 2013)).

A small teleost fish, the zebrafish has a short reproductive cycle and transparent embryos and larvae, enabling an easy assessment of their neurodevelopment (Kimmel CB et al., 1995;Singleman C and Holtzman NGJZ, 2014). Zebrafish have four developmental stages: embryo (until the protruding mouth, $\sim 72$ hours past fertilization, hpf); larva (3-30 days past fertilization, dpf); juvenile fish (attaining a complete pattern of scales and completely losing the larval fin fold; 1-3 months), and adult fish (defined by the production of viable gametes and ability to breed) (Kimmel CB,Ballard WW,Kimmel SR,Ullmann B and Schilling TFJDd, 1995).

The structural and anatomical formation of zebrafish CNS initiates early (Kimmel CB,Ballard WW,Kimmel SR,Ullmann B and Schilling TFJDd, 1995;Papan C and CamposOrtega JAJRsaodb, 1994), with neuronal formation beginning at $16 \mathrm{hpf}$ (Kimmel CB et al., 1991). By 17 hpf, zebrafish brain forms its sub-regions, including the midbrain-hindbrain boundary, cerebellum and thalamus (Gutzman JH et al., 2008;Hanneman E et al., 1988;Kimmel CB,Ballard WW,Kimmel SR,Ullmann B and Schilling TFJDd, 1995;Kimmel CBJAron, 1993). The blood-brain barrier begins to form at $20 \mathrm{hpf}$, demonstrating the well-developed microglia and complete barrier structure at 3 dpf (Herbomel P et al., 1999; Quiñonez-Silvero C et al., 2019). The neural signaling systems, which are ontogenetically homologous to mammalian systems, 
form between 18-32 hpf and include the catecholaminergic (Holzschuh J et al., 2001;Mueller T and Wullimann M, 2015), gamma-aminobutyric acid (GABA)-ergic and glutamatergic systems (Higashijima SI et al., 2004).

\section{Zebrafish model of selected neurodevelopmental disorders}

Zebrafish are actively used to model various aspects of ASD, including sociocognitive deficits and behavioral perseverations (Meshalkina DA et al., 2018; Stewart AM et al., 2014). For example, mimicking ASD-like phenotypes, dizocilpine (MK-801), a non-competitive glutamate N-methyl-D-aspartate (NMDA) receptor antagonist, evokes social deficits (impaired shoaling) in adult fish (Seibt KJ et al., 2011;Zimmermann FF et al., 2016). Zebrafish mimic pathological effects of ASD following larval valproate exposure during neurodevelopment (Dwivedi S et al., 2018), causing overt deficits in social interaction as adults (Zimmermann FF et al., 2017). Valproate exposure during early life also alters brain development, promotes cell proliferation and neurogenesis (including in regions that may contribute to brain overgrowth and macrocephaly), and causes behavioral (e.g., hyperactivity and ASD-like social deficits) and genomic (i.e., gene expression-based; e.g., upregulated adsl (adenylosuccinate lyase) and mbd5 (methyl-CpG binding domain protein 5), downregulated shank3a (SH3 and multiple ankyrin repeat domains $3 a$ ) and tsc1b (tuberous sclerosis complex 1)) responses in embryonic and larval zebrafish (Chen J et al., 2018; Lee S et al., 2018).

Environmental factors that may promote AD clinically include pesticides, solvents and air pollutants (Rossignol DA et al., 2014;Ye BS et al., 2017). Suggesting some predictive validity, zebrafish NDD-related phenotypes can also be corrected by clinically active drugs. For example, risperidone, an atypical antipsychotic used to reduce anxiety and aggression in ASD children (McCracken JT et al., 2002), lowers anxiety-like behavior and cortisol levels caused by acute stress (net chasing) in zebrafish (Idalencio R et al., 2015). Aripiprazole, another atypical antipsychotic used to control irritability, hyperactivity and stereotypies in ASD (Accordino RE et al., 2016), similarly reduces stress response in zebrafish (Barcellos HHD et al., 2016). 
Animal models are important tools for studying the genetic complexity of NDDs (Banerjee S et al., 2014;Hoffman EJ, 2014). For example, the contactin associated protein-like 2 (CNTNAP2) gene is up-regulated in ASD patients (Arking DE et al., 2008;Strauss KA et al., 2006). In line with this, zebrafish $C N T N A P 2$ mutants display nocturnal hyperactive behavior and GABAergic deficits, which can be reversed by treatment with estrogens (e.g., estradiol cypionate and Biochanin A) (Hoffman EJ et al., 2016). A homozygous founder mutation in TRAPPC6B is also associates with human ASD (Marin-Valencia I et al., 2018), and zebrafish trappc6b morphants parallel some human NDD phenotype, displaying microcephaly and neuronal hyperexcitability (Marin-Valencia I,Novarino G,Johansen A,Rosti B,Issa MY,Musaev D,Bhat G,Scott E,Silhavy JL and Stanley V, 2018). Zebrafish knockouts of synaptic ras gtpase activating protein $1(S Y N G A P 1)$ and the SH3 and multiple ankyrin repeat domains 3 (SHANK3) genes recapitulates developmental delay in ASD (Kozol RA et al., 2015), including delayed mid/hindbrain development, motor deficits (unproductive swim attempts) and spontaneous seizure-like behaviors (Kozol RA,Cukier HN,Zou B,Mayo V,De Rubeis S,Cai G,Griswold AJ, Whitehead PL,Haines JL and Gilbert JRJHmg, 2015). The shank3b mutant fish display morphological and behavioral deficits (e.g., reduced locomotion an social interaction) (Liu C-x et al., 2018). Dyrklaa knockout zebrafish exhibit social impairments that reproduce human phenotypes of ASD, as well as lower $c$-fos in hypothalamus vs. wild type, suggesting that the knockout fish brain is less activated by social contexts (Kim O-H et al., 2017). Morpholino shank3b knockdown zebrafish exhibit reduced social interaction, spend less time near conspecifics, and repetitive swimming behaviors in both larvae and adults (Liu C-x et al., 2018).

Common phenotypes associated with ADHD include inattention, impulsiveness and hyperactivity (Winstanley CA et al., 2006), which all can be evaluated in zebrafish (Fontana BD et al., 2019). Both adult and larvae zebrafish can also be useful to model pathological hyperactivity and impulsivity, common in ADHD (Blaser R et al., 2010;Ellis LD et al., 2012; Fontana BD,Franscescon F,Rosemberg DB,Norton WHJ,Kalueff AV and Parker MO, 2019;Saili KS et al., 2012). For example, exposure to 1\% alcohol evokes zebrafish motor 
hyperactivity following dopaminergic stimulation (Nowicki M et al., 2015). Likewise, models have been developed to assess the ability of adult zebrafish to respond to impulsiveness and attention stimulus (Parker MO et al., 2014;Parker MO et al., 2013), as well as to evaluate neurochemical (e.g., monoaminergic) mechanisms of impulsivity in these fish (Parker MO,Brock AJ,Sudwarts A and Brennan CH, 2014).

Genetic risks of ADHD include the gene variants in the latrophilin 3 (LPHN3) gene (Martinez AF et al., 2016), whose lphn3.1 ortholog down-regulation in zebrafish evokes hyperactivity and impulsivity, similarly to ADHD patients (Lange M et al., 2012). The nocturnal hyperactivity behaviors in ADHD are associated with clock genes polymorphisms (Kissling C et al., 2008;Mogavero F et al., 2018). As neuromedin U (Nmu) promotes hyperactivity and inhibits sleep in larvae, the $n m u$ mutant animals present hypoactive phenotype (Chiu CN et al., 2016). In addition, zebrafish knockouts of the clock gene period1b (per $1 b$ ) exhibit similar hyperactivity, impulsivity and circadian disturbances to clinical ADHD (Huang J et al., 2015). The zebrafish Depdc5 knockdown and period1b mutants can also be used as ADHD model in zebrafish, showing both hyperactivity and cognitive deficits (de Calbiac $\mathrm{H}$ et al., 2018;Wang T et al., 2018) (note, however, that hyperactivity is a rather non-specific behavioral alteration, and its presence alone may not be sufficient to mimic ADHD). Zebrafish can also help evaluate new treatments for AHDH. For example, auriculasin, a prenylated isoflavones from Flemingia philippinensis, reduces hyperactivity and increases melatonin and dopamine in period1b-/- zebrafish (Wang T,Liu Y,Liu H,Li C and Wang Y, 2018). Likewise, zebrafish contactin associated protein-like 2 (cntnap2) mutants display ADHD-like hyperactivity and GABAergic deficits in the forebrain, which can be reversed by phytoestrogen biochanin A (Hoffman EJ et al., 2016).

Relevant to modeling ID, ethanol exposure during neurodevelopment induces learning and memory deficits in zebrafish (Carvan III MJ et al., 2004;Fernandes Y et al., 2014;Luchiari AC et al., 2015), strikingly resembling human fetal alcohol syndrome (FAS). The bromodomain PHD finger transcription factor (BPTF) variants are found in patients with global developmental delay/ID, speech delay, postnatal microcephaly, and dysmorphic features (Stankiewicz P et al., 
2017). Zebrafish knockout of bptf causes smaller head size and abnormal craniofacial patterning (Stankiewicz P,Khan TN,Szafranski P,Slattery L,Streff H,Vetrini F,Bernstein JA,Brown CW,Rosenfeld JA and Rednam S, 2017). The X-linked genetic syndrome associated with mutations in TAF1 gene presents global developmental delay and ID. Zebrafish morpholino of tafl ortholog reduces the optic tectum, demonstrating that mutations in TAF1 play a critical role in the development of this X-linked ID (O'Rawe JA et al., 2015). In addition, mutations in exosome component 3 (EXOSC3) are associated with global developmental delay, cerebellar atrophy, progressive microcephaly and pontocerebellar hypoplasia type 1 (Wan J et al., 2012). Morpholino knockdown of exosc 3 in zebrafish embryos causes embryonic microcephaly and poor motility, resembling some of clinical features (Wan J,Yourshaw M,Mamsa H,RudnikSchöneborn S,Menezes MP,Hong JE,Leong DW,Senderek J,Salman MS and Chitayat D, 2012). Patients with dysfunction of Cyclin K (CCNK) display developmental delay, ID and language defects (Fan Y et al., 2018). Functional assay in zebrafish larvae show that Ccnk knockdown impairs brain and spinal cord development (Fan Y,Yin W,Hu B,Kline AD,Zhang VW,Liang D,Sun Y,Wang L,Tang S and Powis Z, 2018). Another candidate gene for reading problems and mild ID is CTNND2, and both humans and zebrafish with haploinsufficiency of this gene present cognitive dysfunction (Hofmeister W et al., 2015).

As several motor disorders are also classified as NDDs, zebrafish emerge as a useful tool to unravel possible aberrant control of the motor system (Schilling TFJZ, 2002). For example, larvae exposure to ketamine evokes anxiety-like behavior and lower swimming speed (Félix LM et al., 2017) - the effects diminished by acetyl 1-carnitine, which promotes neuroprotective effects and reduces the degeneration of Rohon-Beard sensory neurons in zebrafish (Cuevas E et al., 2013). The Rett syndrome is an X-linked neurodevelopmental disorder with mental retardation and a rapid regression of motor and cognitive skills. Mutations in the transcription factor MECP2 gene are present in $>90 \%$ of Rett syndrome patients (Amir RE et al., 1999), and the Mecp2 knockout zebrafish display reduced swimming activity (Pietri T et al., 2013) and aberrant CNS brain-derived neurotrophic factor ( $b d n f)$ gene expression (Nozawa K et al., 2017). 
Microcephaly is a general comorbidity of many NDDs (Watemberg N et al., 2002; Woods CGJCoin, 2004), and zebrafish may help examine genetic implications and the molecular mechanisms of this disorder (Kim H-T et al., 2011;Novorol C et al., 2013). The autosomal recessive primary microcephaly $(\mathrm{MCPH})$ is characterized by smaller cortices, which can be evaluated by expression of the abnormal spindle-like microcephaly associated gene (aspm) in zebrafish (Kim H-T,Lee M-S,Choi J-H,Jung J-Y,Ahn D-G,Yeo S-Y,Choi D-K,Kim C-HJB and communications br, 2011). Similarly, Fancd2 (fanconi anemia complementation group D2) mutants zebrafish also present microcephaly and microphthalmia, paralleling clinical phenotypes (Liu TX et al., 2003). The loss-of-function and missense variants in KIAA1109 are associated to autosomal-recessive multi-system Alkuraya-Kucinskas syndrome, and knockdown of the orthologous gene in zebrafish causes embryonic hydrocephaly (Gueneau L et al., 2018). Kabuki syndrome is a rare multiple congenital anomaly syndrome characterized by global developmental delay and ID due to mutations in the KMT2D and $K D M 6 A$ genes. Zebrafish knockdown of $k m t 2 d$ and the two zebrafish paralogues $k d m 6 a$ and $k d m 6 a l$ present developmental abnormalities similar to Kabuki syndrome, as kdm6a and kmt2d morphants exhibit severe abnormalities in brain development (Van Laarhoven PM et al., 2015).

Finally, schizophrenia is a critical, severely debilitating disorder, which is relevant to NDDs, affects approximately $1 \%$ globally and causes cognitive, emotional, social and perceptual dysfunctions (Association AP, 2013). Schizophrenia-like phenotypes can be studied in zebrafish using various tests to assess fish locomotor activity (Daggett J, 2016; Kysil EV et al., 2017;Wang L et al., 2016), as well as social (Wang L,Jiang W,Lin Q,Zhang Y and Zhao C, 2016), cognitive (Daggett J, 2016;Meshalkina DA et al., 2017) and aggressive behaviors (de Abreu MS et al., 2019;Zabegalov KN et al., 2019), all commonly observed in schizophrenic patients. Schizophrenia-like states can also be induced experimentally, for example, mimicking the hypofunction of glutamatergic N-methyl-D-aspartate (NMDA) signaling (Farber NB, 2003). In zebrafish, a pro-psychotic drug dizocilpine (MK- 801) potently modulates a wide range of behavioral phenotypes, including those directly relevant to psychoses, such as motor 
hyperactivity and social deficits, which are also reversed by clinically active antipsychotics sulpiride and olanzapine (Seibt KJ et al., 2010;Seibt KJ et al., 2011). In addition, several brain genes are associated with schizophrenia and can be evaluated in zebrafish, including the disrupted in schizophrenia 1 (discl) and neuregulin 1 ( $\mathrm{nrgl}$ ) genes (Owen MJ et al., 2009), as well as glutamatergic and GABA-ergic genes, such as dysbindin (DTNBP1), catechol-Omethyltransferase (COMT), proline dehydrogenase (PRODH), Metabotropic glutamate receptor-3 (GRM3; mGluR3), regulator of G-protein signaling 4 (RGS4) (Harrison PJ and Weinberger DRJMp, 2005;O’Tuathaigh CMP et al., 2007).

\section{General discussion}

Evidence summarized here suggests that zebrafish emerge as an important new model to study NDDs. Possessing several practical advantages, such as chorion transparency that allows easy observation of development, low cost and rapid development (Beliaeva $\mathrm{N}$ et al., 2010; Tavares B and Lopes SSJAmp, 2013) (Fig. 1), zebrafish also present conserved GABAergic (Hortopan GA et al., 2010;Roy B and Ali DWJN, 2014), monoaminergic (Irons T et al., 2013;Souza BR and Tropepe VJRitn, 2011;Yamamoto K et al., 2010), purinergic (Piato AL et al., 2011;Zimmermann FF,Gaspary KV,Siebel AM,Leite CE,Kist LW,Bogo MR and Bonan CDJMn, 2017), glutamatergic (Rico EP et al., 2010;Vitale W, 2012) and melatonergic (Genario R et al., 2019) systems, as well as well-defined neuronal complexes (Jin Y et al., 2018;Kabashi E et al., 2011;Panula P et al., 2006). In addition, zebrafish is an important model to assess chemical, neurotoxic and genetic insults during neural development (Giordani S and d'Amora MJFiN, 2018;Wang S et al., 2018). Zebrafish are further suitable for studying NDDs (Dorsemans A-C et al., 2017) due to high neuroplasticity, enabling the analyses of multiple neuronal adaptations (Ghosh S and Hui SP, 2016) and their behavioral (e.g., sociality or emotionality) correlates (Teles MC et al., 2016) controlled by relatively well-defined circuits

(Perathoner S et al., 2016). The growing number of zebrafish genes whose orthologs have been implicated in human NDDs (Fontana BD,Franscescon F, Rosemberg DB,Norton WHJ,Kalueff AV and Parker MO, 2019;Meshalkina DA et al., 2018;Vaz R et al., 2019) supports the value of 
this organism for developing new CNS targets. Finally, important advantages of zebrafish models of NDDs (over mammals) include their high-throughput potential (Jordi J et al., 2018) and better compliance, as lower vertebrates, with bioethical animal experimentation and 3R principles (de Abreu MS et al., 2019).

However, as other in vivo models, zebrafish present certain limitations in regard to modeling NDDs. For example, zebrafish show overt differences in physiology compared to mammals, such as the external fertilization that does not mimic uterine development in mammals (d'Amora M and Giordani S, 2018). Another problem is that zebrafish present rather limited range of behavioral phenomena (e.g., it is unclear if depression-like states exist in zebrafish (de Abreu MS et al., 2018)) compared to other, much better studied (e.g., rodent) NDDs models. Moreover, unlike mammals, zebrafish does not exhibit some critical brain areas (most notably, cerebral cortex (Kalueff AV et al., 2014)). It is also impossible to mimic some NDDs in zebrafish (e.g., speech sound disorder, stuttering, developmental coordination disorder, tic disorders, communication/language disorder), or to evaluate the role of neurodevelopment during gestation (due to external fertilization in fish). While zebrafish do present a complex behavioral repertoire (Ariyomo TO et al., 2013;Blaser R,Chadwick L and McGinnis GJBbr, 2010;Dreosti E et al., 2015;Kalueff AV et al., 2013), the face validity of zebrafish models for NDDs remains unclear, and it is unlikely that all NDD symptoms can be recapitulated. In addition, unlike mammals, some zebrafish genes are duplicated as a result of teleost-specific genome duplication event (Howe $\mathrm{K}$ et al., 2013), with an average of $20-24 \%$ of genes duplicated (Howe K, Clark MD, Torroja CF, Torrance J, Berthelot C, Muffato M, Collins JE, Humphray S, McLaren K, Matthews L, McLaren S, Sealy I, Caccamo M, Churcher C, Scott C, Barrett JC, Koch R, Rauch GJ, White S, Chow W, Kilian B, Quintais LT, Guerra-Assunção JA, Zhou Y, Gu Y, Yen J, Vogel JH, Eyre T, Redmond S, Banerjee R, Chi J, Fu B, Langley E, Maguire SF, Laird GK, Lloyd D, Kenyon E, Donaldson S, Sehra H, Almeida-King J, Loveland J, Trevanion S, Jones M, Quail M, Willey D, Hunt A, Burton J, Sims S, McLay K, Plumb B, Davis J, Clee C, Oliver K, Clark R, Riddle C, Elliot D, Eliott D, Threadgold G, Harden G, Ware D, Begum S, Mortimore B, Mortimer B, Kerry 
G, Heath P, Phillimore B, Tracey A, Corby N, Dunn M, Johnson C, Wood J, Clark S, Pelan S, Griffiths G, Smith M, Glithero R, Howden P, Barker N, Lloyd C, Stevens C, Harley J, Holt K, Panagiotidis G, Lovell J, Beasley H, Henderson C, Gordon D, Auger K, Wright D, Collins J, Raisen C, Dyer L, Leung K, Robertson L, Ambridge K, Leongamornlert D, McGuire S, Gilderthorp R, Griffiths C, Manthravadi D, Nichol S, Barker G, Whitehead S, Kay M, Brown J, Murnane C, Gray E, Humphries M, Sycamore N, Barker D, Saunders D, Wallis J, Babbage A, Hammond S, Mashreghi-Mohammadi M, Barr L, Martin S, Wray P, Ellington A, Matthews N, Ellwood M, Woodmansey R, Clark G, Cooper J, Tromans A, Grafham D, Skuce C, Pandian R, Andrews R, Harrison E, Kimberley A, Garnett J, Fosker N, Hall R, Garner P, Kelly D, Bird C, Palmer S, Gehring I, Berger A, Dooley CM, Ersan-Ürün Z, Eser C, Geiger H, Geisler M, Karotki L, Kirn A, Konantz J, Konantz M, Oberländer M, Rudolph-Geiger S, Teucke M, Lanz C, Raddatz G, Osoegawa K, Zhu B, Rapp A, Widaa S, Langford C, Yang F, Schuster SC, Carter NP, Harrow J, Ning Z, Herrero J, Searle SM, Enright A, Geisler R, Plasterk RH, Lee C, Westerfield M, de Jong PJ, Zon LI, Postlethwait JH, Nüsslein-Volhard C, Hubbard TJ, Roest Crollius H, Rogers J and Stemple DL, 2013). This can result in redundant functions of various key brain genes related to NDDs, and may provide phenotypic buffering and/or complicating the generation of genetargeted (knockout or knockdown) diseases models (Kozol RA et al., 2016; Sakai C et al., 2018).

Notably, the long-term effect of many zebrafish mutants is not characterized for adult zebrafish behavior, calling into question its predictive validity. Thus, studies aiming to characterize in detail the face and predictive validity of zebrafish NDDs models are still necessary if we are to understand the mechanisms of these disorders across the lifespan.

Nevertheless, mounting evidence suggests that zebrafish models can be used to screen novel treatments for various NDDs. For example, screening of behavioral effects of over 10000 drugs in larval zebrafish (Jordi J,Guggiana-Nilo D,Bolton AD,Prabha S,Ballotti K,Herrera K,Rennekamp AJ,Peterson RT,Lutz TA and Engert F, 2018) suggests several compounds which may help develop new ADHD therapies and improve our understanding of mechanisms and neural circuits involved in this disorder. Still, a large translational gap exists for animal models 
of NDDs, including zebrafish models relevant to these conditions. In general, the translatability of findings obtained in animal models is generally associated with the range of mechanisms and phenotypic profiles that the animal model can address (Zeiss CJ and Johnson LK, 2017). The factors that may contribute to the reproducibility-translatability gap include relationships between the model choice (e.g., intended goal of the intervention) and the integration of biomarker data with outcome measures that are clinically relevant to humans (Zeiss CJJIj, 2017). Despite clear advantages as a model organism (discussed above), our present understanding of zebrafish NDD-related phenotypes and their molecular mechanisms remained limited, as is the number of established behavioral models and tests relevant to mimicking these disorders. Nevertheless, as animal models continue to play a key role in the identification of genetic and molecular targets to develop safer and more effective treatments for NDD, the zebrafish is emerging as a potentially promising species to generate important insights into pharmacological and genetic roles of NDDs. With many questions yet remaining open in this field (Table 1), this calls for further research utilizing zebrafish models of NDDs.

\section{Acknowledgement}

This research is supported by the Russian Science Foundation. KAD is supported by the Russian Foundation for Basic Research and the SPSU Rector's Productivity Fellowship for PhD students. ACVVG is supported by the Fundação de Amparo à Pesquisa do Estado do Rio Grande do Sul (FAPERGS) research fellowships 17/2551-0001-269-0. AVK is the President of the International Stress and Behavior Society (ISBS, www.stress-and-behavior) that coordinated this multi-laboratory collaborative project.

\section{Conflict of interest}

The authors declare no conflict of interest 
Figure 1. Schematic diagram emphasizing the advantages of using zebrafish to study neurodevelopmental disorders and their risk factors.

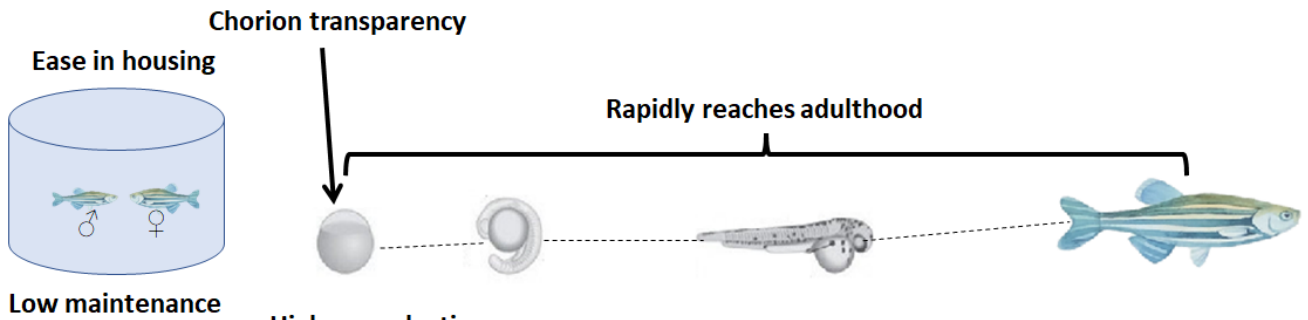

cost

High reproduction

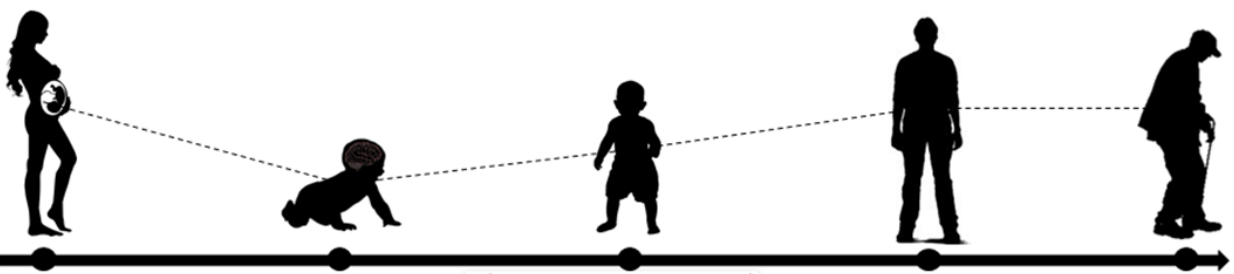

Neurodevelopmental disorders

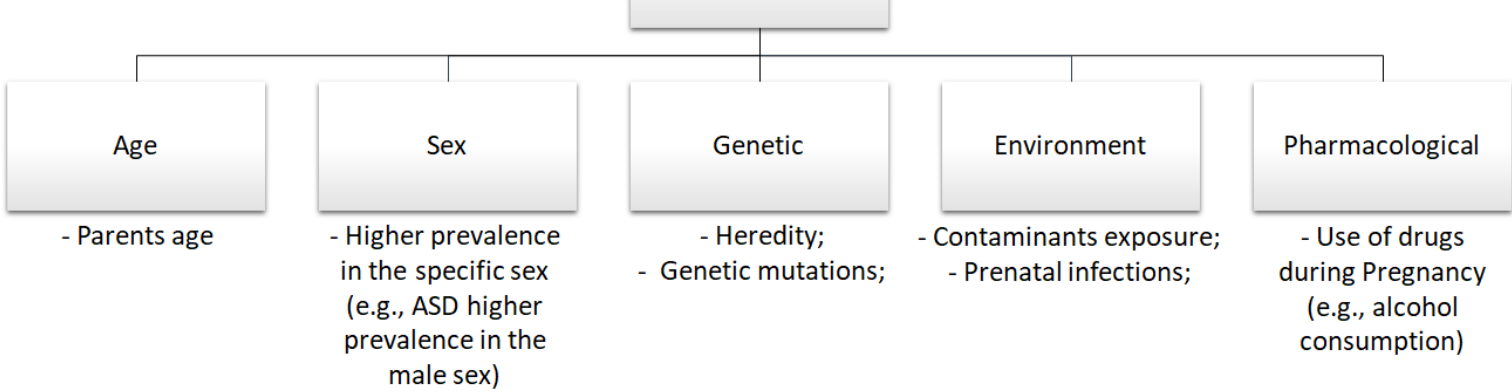




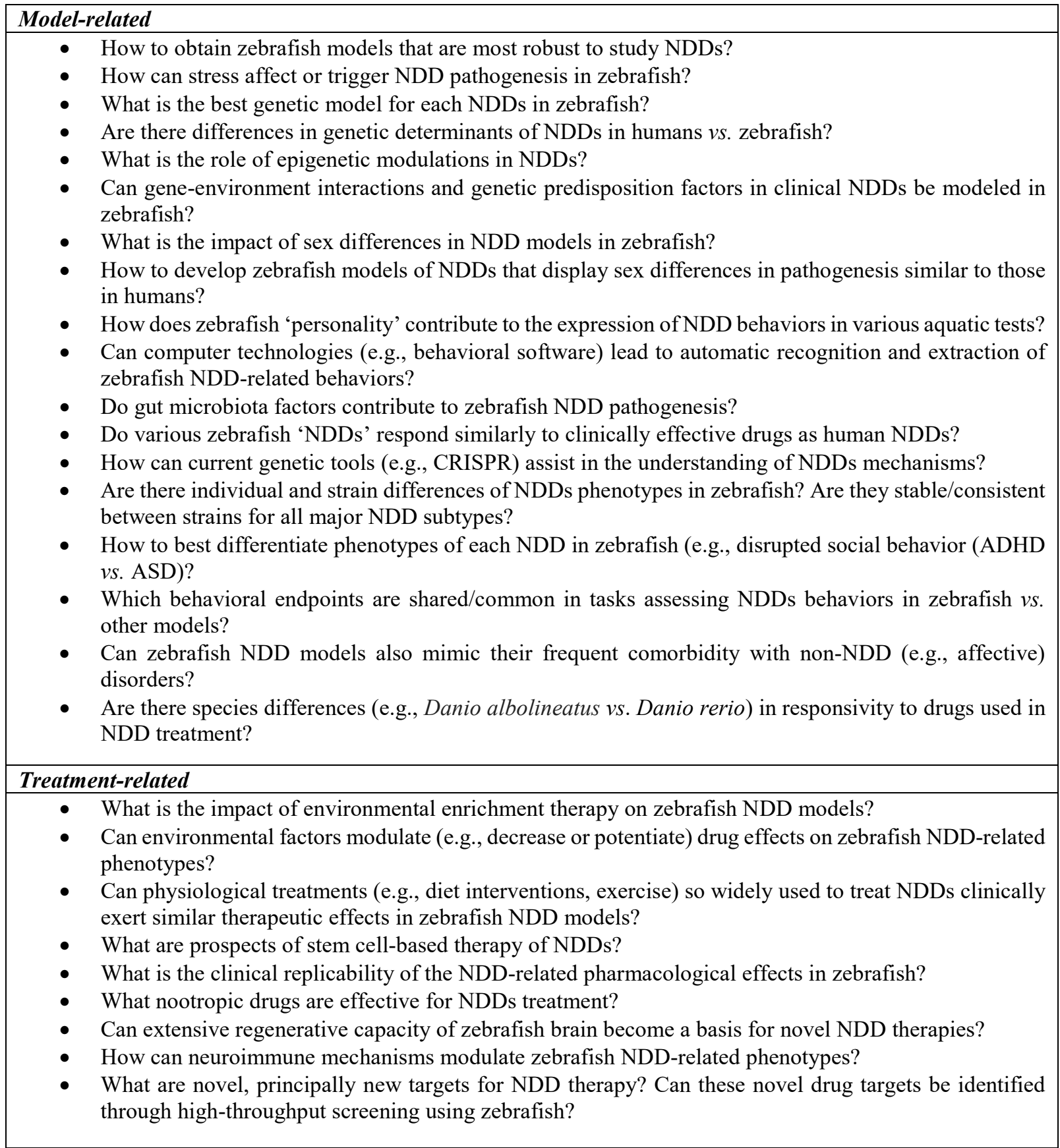




\section{References}

Accordino RE, Kidd C, Politte LC, Henry CA, McDougle CJ (2016), Psychopharmacological interventions in autism spectrum disorder. Expert opinion on pharmacotherapy 17:937-952.

American Psychiatric A (2013) Diagnostic and statistical manual of mental disorders (DSM- ${ }^{\circledR}$ ). American Psychiatric Pub.

Amir RE, Van den Veyver IB, Wan M, Tran CQ, Francke U, Zoghbi HY (1999), Rett syndrome is caused by mutations in X-linked MECP2, encoding methyl-CpG-binding protein 2. Nature genetics 23:185.

Ariyomo TO, Carter M, Watt PJ (2013), Heritability of boldness and aggressiveness in the zebrafish. Behav Genet 43:161-167.

Arking DE, Cutler DJ, Brune CW, Teslovich TM, West K, Ikeda M, Rea A, Guy M, et al. (2008), A common genetic variant in the neurexin superfamily member CNTNAP2 increases familial risk of autism. 82:160164.

Association AP (2013) Diagnostic and Statistical Manual of Mental Disorders. In: Diagnostic and Statistical Manual of Mental Disorders, vol. American Psychiatric Association.

Banerjee S, Bhat M, Riordan MJFicn (2014), Genetic aspects of autism spectrum disorders: insights from animal models. 8:58.

Barcellos HHD, Kalichak F, da Rosa JGS, Oliveira TA, Koakoski G, Idalencio R, de Abreu MS, Giacomini ACV, et al. (2016), Waterborne aripiprazole blunts the stress response in zebrafish. Scientific Reports 6:4.

Beliaeva N, Kashirtseva V, Medvedeva N, Khudoklinova I, Ipatova O, Archakov AJBk (2010), Zebrafish as a model organism for biomedical studies. 56:120-131.

Best J, Alderton WKJNd, treatment (2008), Zebrafish: an in vivo model for the study of neurological diseases. 4:567.

Blaser R, Chadwick L, McGinnis GJBbr (2010), Behavioral measures of anxiety in zebrafish (Danio rerio). 208:56-62.

Carvan III MJ, Loucks E, Weber DN, Williams FEJN, teratology (2004), Ethanol effects on the developing zebrafish: neurobehavior and skeletal morphogenesis. 26:757-768.

Chen J, Lei L, Tian L, Hou F, Roper C, Ge X, Zhao Y, Chen Y, et al. (2018), Developmental and behavioral alterations in zebrafish embryonically exposed to valproic acid (VPA): An aquatic model for autism. Neurotoxicology and teratology 66:8-16.

Chiu CN, Rihel J, Lee DA, Singh C, Mosser EA, Chen S, Sapin V, Pham U, et al. (2016), A zebrafish genetic screen identifies neuromedin $U$ as a regulator of sleep/wake states. Neuron 89:842-856.

Cuevas E, Trickler WJ, Guo X, Ali SF, Paule MG, Kanungo JJN, teratology (2013), Acetyl L-carnitine protects motor neurons and Rohon-Beard sensory neurons against ketamine-induced neurotoxicity in zebrafish embryos. 39:69-76.

Currenti SAJC, neurobiology m (2010), Understanding and determining the etiology of autism. 30:161171.

d'Amora M, Giordani S (2018), The Utility of Zebrafish as a Model for Screening Developmental Neurotoxicity. Frontiers in Neuroscience 12:976.

Daggett J, Evaluation and characterisation of two zebrafish models of schizophrenia, University of St Andrews, 2016.

de Abreu MS, Friend AJ, Deming KA, Amstislavskaya TG, Bao WD, Kalueff AV (2018), Zebrafish models: do we have valid paradigms for depression? Journal of Pharmacological and Toxicological Methods 94:16-22.

de Abreu MS, Giacomini ACVV, Echevarria DJ, Kalueff AV (2019), Legal aspects of zebrafish neuropharmacology and neurotoxicology research. Regulatory Toxicology and Pharmacology 101:6570.

de Abreu MS, Giacomini ACVV, Genario R, Dos Santos BE, da Rosa LG, Demin KA, Wappler-Guzzetta EA, Kalueff AV (2019), Neuropharmacology, pharmacogenetics and pharmacogenomics of aggression: The zebrafish model. Pharmacol Res 141:602-608.

de Calbiac H, Dabacan A, Marsan E, Tostivint H, Devienne G, Ishida S, Leguern E, Baulac S, et al. (2018), Depdc5 knockdown causes mTOR-dependent motor hyperactivity in zebrafish. Annals of clinical and translational neurology 5:510-523. 
Dorsemans A-C, Soulé S, Weger M, Bourdon E, Lefebvre d'Hellencourt C, Meilhac O, Diotel N (2017), Impaired constitutive and regenerative neurogenesis in adult hyperglycemic zebrafish. Journal of Comparative Neurology 525:442-458.

Dreosti E, Lopes G, Kampff AR, Wilson SW (2015), Development of social behavior in young zebrafish. Frontiers in neural circuits 9:39.

Dwivedi S, Medishetti R, Rani R, Sevilimedu A, Kulkarni P, Yogeeswari PJJop, methods t (2018), Larval zebrafish model for studying the effects of valproic acid on neurodevelopment: An approach towards modeling autism.

Ellis LD, Seibert J, Soanes $\mathrm{KHJBr}$ (2012), Distinct models of induced hyperactivity in zebrafish larvae. 1449:46-59.

Elsabbagh M, Divan G, Koh YJ, Kim YS, Kauchali S, Marcín C, Montiel-Nava C, Patel V, et al. (2012), Global prevalence of autism and other pervasive developmental disorders. Autism research 5:160-179.

Fan Y, Yin W, Hu B, Kline AD, Zhang VW, Liang D, Sun Y, Wang L, et al. (2018), De Novo Mutations of CCNK Cause a Syndromic Neurodevelopmental Disorder with Distinctive Facial Dysmorphism. The American Journal of Human Genetics 103:448-455.

Farber NB (2003), The NMDA receptor hypofunction model of psychosis. Annals of the New York Academy of Sciences 1003:119-130.

Félix LM, Antunes LM, Coimbra AM, Valentim AMJP (2017), Behavioral alterations of zebrafish larvae after early embryonic exposure to ketamine. 234:549-558.

Fernandes Y, Tran S, Abraham E, Gerlai RJBbr (2014), Embryonic alcohol exposure impairs associative learning performance in adult zebrafish. 265:181-187.

Fontana BD, Franscescon F, Rosemberg DB, Norton WHJ, Kalueff AV, Parker MO (2019), Zebrafish models for attention deficit hyperactivity disorder (ADHD). Neuroscience \& Biobehavioral Reviews.

Gathercole SE, Alloway TPJJoCP, Psychiatry (2006), Practitioner review: Short-term and working memory impairments in neurodevelopmental disorders: Diagnosis and remedial support. 47:4-15.

Gatto CL, Broadie KJCoin (2011), Drosophila modeling of heritable neurodevelopmental disorders. 21:834-841.

Genario R, Giacomini AC, Demin KA, dos Santos BE, Marchiori NI, Volgin AD, Bashirzade A, Amstislavskaya TG, et al. (2019), The evolutionarily conserved role of melatonin in CNS disorders and behavioral regulation: translational lessons from zebrafish.

Ghosh S, Hui SP (2016), Regeneration of Zebrafish CNS: Adult Neurogenesis. Neural Plasticity 2016:5815439.

Giordani S, d'Amora MJFiN (2018), The utility of Zebrafish as a model for screening developmental neurotoxicity. 12:976.

Gueneau L, Fish RJ, Shamseldin HE, Voisin N, Mau-Them FT, Preiksaitiene E, Monroe GR, Lai A, et al. (2018), KIAA1109 variants are associated with a severe disorder of brain development and arthrogryposis. The American Journal of Human Genetics 102:116-132.

Gutzman JH, Graeden EG, Lowery LA, Holley HS, Sive HJMod (2008), Formation of the zebrafish midbrain-hindbrain boundary constriction requires laminin-dependent basal constriction. 125:974-983. Hanneman E, Trevarrow B, Metcalfe WK, Kimmel CB, Westerfield MJD (1988), Segmental pattern of development of the hindbrain and spinal cord of the zebrafish embryo. 103:49-58.

Harrison PJ, Weinberger DRJMp (2005), Schizophrenia genes, gene expression, and neuropathology: on the matter of their convergence. 10:40.

Herbomel P, Thisse B, Thisse CJD (1999), Ontogeny and behaviour of early macrophages in the zebrafish embryo. 126:3735-3745.

Higashijima SI, Mandel G, Fetcho JRJJoCN (2004), Distribution of prospective glutamatergic, glycinergic, and GABAergic neurons in embryonic and larval zebrafish. 480:1-18.

Hoffman EJ (2014) Functional Analysis of Genes Associated with Autism Spectrum Disorders in a Zebrafish Model System. Yale University.

Hoffman EJ, Turner KJ, Fernandez JM, Cifuentes D, Ghosh M, ljaz S, Jain RA, Kubo F, et al. (2016), Estrogens suppress a behavioral phenotype in zebrafish mutants of the autism risk gene, CNTNAP2. Neuron 89:725-733.

Hoffman EJ, Turner KJ, Fernandez JM, Cifuentes D, Ghosh M, ljaz S, Jain RA, Kubo F, et al. (2016), Estrogens suppress a behavioral phenotype in zebrafish mutants of the autism risk gene, CNTNAP2. 89:725-733. 
Hofmeister W, Nilsson D, Topa A, Anderlid B-M, Darki F, Matsson H, Páez IT, Klingberg T, et al. (2015), CTNND2-a candidate gene for reading problems and mild intellectual disability. Journal of medical genetics 52:111-122.

Holzschuh J, Ryu S, Aberger F, Driever WJMod (2001), Dopamine transporter expression distinguishes dopaminergic neurons from other catecholaminergic neurons in the developing zebrafish embryo. 101:237-243.

Hortopan GA, Dinday MT, Baraban SCJJoN (2010), Spontaneous seizures and altered gene expression in GABA signaling pathways in a mind bomb mutant zebrafish. 30:13718-13728.

Howe K, Clark MD, Torroja CF, Torrance J, Berthelot C, Muffato M, Collins JE, Humphray S, et al. (2013), The zebrafish reference genome sequence and its relationship to the human genome. Nature 496:498503.

Huang J, Zhong Z, Wang M, Chen X, Tan Y, Zhang S, He W, He X, et al. (2015), Circadian modulation of dopamine levels and dopaminergic neuron development contributes to attention deficiency and hyperactive behavior. 35:2572-2587.

Idalencio R, Kalichak F, Rosa JGS, de Oliveira TA, Koakoski G, Gusso D, de Abreu MS, Giacomini ACV, et al. (2015), Waterborne risperidone decreases stress response in zebrafish. 10:e0140800.

Irons T, Kelly P, Hunter D, Macphail R, Padilla SJPB, Behavior (2013), Acute administration of dopaminergic drugs has differential effects on locomotion in larval zebrafish. 103:792-813.

Jin Y, Choi J, Won J, Hong YJM (2018), The relationship between autism spectrum disorder and melatonin during fetal development. 23:198.

Jordi J, Guggiana-Nilo D, Bolton AD, Prabha S, Ballotti K, Herrera K, Rennekamp AJ, Peterson RT, et al. (2018), High-throughput screening for selective appetite modulators: A multibehavioral and translational drug discovery strategy. Science Advances 4:eaav1966.

Kabashi E, Brustein E, Champagne N, Drapeau PJBeBA-MBoD (2011), Zebrafish models for the functional genomics of neurogenetic disorders. 1812:335-345.

Kalueff AV, Echevarria DJ, Stewart AM (2014), Gaining translational momentum: More zebrafish models for neuroscience research. Progress in Neuro-Psychopharmacology and Biological Psychiatry 55:1-6.

Kalueff AV, Gebhardt M, Stewart AM, Cachat JM, Brimmer M, Chawla JS, Craddock C, Kyzar EJ, et al. (2013), Towards a comprehensive catalog of zebrafish behavior 1.0 and beyond. Zebrafish 10:70-86.

Kalueff AV, Stewart AM, Gerlai RJTips (2014), Zebrafish as an emerging model for studying complex brain disorders. 35:63-75.

Khan KM, Collier AD, Meshalkina DA, Kysil EV, Khatsko SL, Kolesnikova T, Morzherin YY, Warnick JE, et al. (2017), Zebrafish models in neuropsychopharmacology and CNS drug discovery. 174:1925-1944.

Kim H-T, Lee M-S, Choi J-H, Jung J-Y, Ahn D-G, Yeo S-Y, Choi D-K, Kim C-HJB, et al. (2011), The microcephaly gene aspm is involved in brain development in zebrafish. 409:640-644.

Kim O-H, Cho H-J, Han E, Hong TI, Ariyasiri K, Choi J-H, Hwang K-S, Jeong Y-M, et al. (2017), Zebrafish knockout of Down syndrome gene, DYRK1A, shows social impairments relevant to autism. Molecular autism 8:50.

Kimmel CB, Ballard WW, Kimmel SR, Ullmann B, Schilling TFJDd (1995), Stages of embryonic development of the zebrafish. 203:253-310.

Kimmel CB, Hatta K, Eisen JSJD (1991), Genetic control of primary neuronal development in zebrafish. 113:47-57.

Kimmel CBJAron (1993), Patterning the brain of the zebrafish embryo. 16:707-732.

Kissling C, Retz W, Wiemann S, Coogan AN, Clement RM, Hünnerkopf R, Conner AC, Freitag CM, et al. (2008), A polymorphism at the $3^{\prime}$-untranslated region of the CLOCK gene is associated with adult attention-deficit hyperactivity disorder. 147:333-338.

Kozol RA, Abrams AJ, James DM, Buglo E, Yan Q, Dallman JE (2016), Function Over Form: Modeling Groups of Inherited Neurological Conditions in Zebrafish. Frontiers in molecular neuroscience 9:55-55.

Kozol RA, Cukier HN, Zou B, Mayo V, De Rubeis S, Cai G, Griswold AJ, Whitehead PL, et al. (2015), Two knockdown models of the autism genes SYNGAP1 and SHANK3 in zebrafish produce similar behavioral phenotypes associated with embryonic disruptions of brain morphogenesis. 24:4006-4023.

Krakowiak P, Walker CK, Bremer AA, Baker AS, Ozonoff S, Hansen RL, Hertz-Picciotto IJP (2012), Maternal metabolic conditions and risk for autism and other neurodevelopmental disorders.peds. 2011-2583.

Kysil EV, Meshalkina DA, Frick EE, Echevarria DJ, Rosemberg DB, Maximino C, Lima MG, Abreu MS, et al. (2017), Comparative Analyses of Zebrafish Anxiety-Like Behavior Using Conflict-Based Novelty Tests. Zebrafish 14:197-208. 
Lainhart JEJIRoP (1999), Psychiatric problems in individuals with autism, their parents and siblings. 11:278-298.

Lange M, Norton W, Coolen M, Chaminade M, Merker S, Proft F, Schmitt A, Vernier P, et al. (2012), The ADHD-susceptibility gene Iphn3. 1 modulates dopaminergic neuron formation and locomotor activity during zebrafish development. 17:946.

Lee S, Chun H-S, Lee J, Park H-J, Kim K-T, Kim C-H, Yoon S, Kim W-K (2018), Plausibility of the zebrafish embryos/larvae as an alternative animal model for autism: A comparison study of transcriptome changes. PloS one 13:e0203543.

Lewis DA, Levitt PJAron (2002), Schizophrenia as a disorder of neurodevelopment. 25:409-432.

Liu C-x, Li C-y, Hu C-c, Wang Y, Lin J, Jiang Y-h, Li Q, Xu X (2018), CRISPR/Cas9-induced shank3b mutant zebrafish display autism-like behaviors. Molecular autism 9:23.

Liu C-x, Li C-y, Hu C-c, Wang Y, Lin J, Jiang Y-h, Li Q, Xu XJMa (2018), CRISPR/Cas9-induced shank3b mutant zebrafish display autism-like behaviors. 9:23.

Liu TX, Howlett NG, Deng M, Langenau DM, Hsu K, Rhodes J, Kanki JP, D'Andrea AD, et al. (2003), Knockdown of zebrafish Fancd2 causes developmental abnormalities via p53-dependent apoptosis. 5:903-914.

Lou HJAP (1996), Etiology and pathogenesis of Attention-deficit Hyperactivity Disorder (ADHD): significance of prematurity and perinatal hypoxic-haemodynamic encephalopathy. 85:1266-1271.

Luchiari AC, Salajan DC, Gerlai RJBbr (2015), Acute and chronic alcohol administration: effects on performance of zebrafish in a latent learning task. 282:76-83.

MacRae CA, Peterson RTJNrDd (2015), Zebrafish as tools for drug discovery. 14:721.

Marin-Valencia I, Novarino G, Johansen A, Rosti B, Issa MY, Musaev D, Bhat G, Scott E, et al. (2018), A homozygous founder mutation in TRAPPC6B associates with a neurodevelopmental disorder characterised by microcephaly, epilepsy and autistic features. Journal of medical genetics 55:48-54.

Martens G, van Loo KJCg (2007), Genetic and environmental factors in complex neurodevelopmental disorders. 8:429-444.

Martinez AF, Abe Y, Hong S, Molyneux K, Yarnell D, Löhr H, Driever W, Acosta MT, et al. (2016), An ultraconserved brain-specific enhancer within ADGRL3 (LPHN3) underpins attentiondeficit/hyperactivity disorder susceptibility. Biological psychiatry 80:943-954.

Mayes SD, Calhoun SL, Crowell EWJJold (2000), Learning disabilities and ADHD: Overlapping spectrum disorders. 33:417-424.

Mayes SD, Calhoun SLCN (2007), Learning, attention, writing, and processing speed in typical children and children with ADHD, autism, anxiety, depression, and oppositional-defiant disorder. 13:469-493.

McCracken JT, McGough J, Shah B, Cronin P, Hong D, Aman MG, Arnold LE, Lindsay R, et al. (2002), Risperidone in children with autism and serious behavioral problems. 347:314-321.

Meshalkina DA, Kizlyk MN, Kysil EV, Collier AD, Echevarria DJ, Abreu MS, Barcellos L, Song C, et al. (2018), Zebrafish models of autism spectrum disorder. 299:207-216.

Meshalkina DA, Kizlyk MN, Kysil EV, Collier AD, Echevarria DJ, Abreu MS, Barcellos LG, Song C, et al. (2017), Understanding zebrafish cognition. Behavioural Processes 141:229-241.

Meshalkina DA, Kizlyk MN, Kysil EV, Collier AD, Echevarria DJ, Abreu MS, Barcellos LG, Song C, et al. (2018), Zebrafish models of autism spectrum disorder. Experimental Neurology 299:207-216.

Meyer U, Feldon J, Fatemi SHJN, Reviews B (2009), In-vivo rodent models for the experimental investigation of prenatal immune activation effects in neurodevelopmental brain disorders. 33:10611079.

Miles JHJGiM (2011), Autism spectrum disorders-a genetics review. 13:278.

Millichap JGJP (2008), Etiologic classification of attention-deficit/hyperactivity disorder. 121:e358-e365. Moeschler JB, Shevell M (2014), Comprehensive evaluation of the child with intellectual disability or global developmental delays. Pediatrics 134:e903-e918.

Mogavero F, Jager A, Glennon JCJN, Reviews B (2018), Clock genes, ADHD and aggression. 91:51-68.

Mueller T, Wullimann M (2015) Atlas of early zebrafish brain development: a tool for molecular neurogenetics. Academic Press.

Newcorn JH, Leikauf J, Johnson B, Krone B, Halperin JMJP (2015), Neurodevelopmental Disorders: Attention-Deficit/Hyperactivity Disorder. 1:748-764.

Nigg JTJJoCC, Psychology A (2012), Future directions in ADHD etiology research. 41:524-533. 
Novorol C, Burkhardt J, Wood KJ, Iqbal A, Roque C, Coutts N, Almeida AD, He J, et al. (2013), Microcephaly models in the developing zebrafish retinal neuroepithelium point to an underlying defect in metaphase progression. 3:130065.

Nowicki M, Tran S, Chatterjee D, Gerlai R (2015), Inhibition of phosphorylated tyrosine hydroxylase attenuates ethanol-induced hyperactivity in adult zebrafish (Danio rerio). Pharmacology Biochemistry and Behavior 138:32-39.

Nozawa K, Lin Y, Kubodera R, Shimizu Y, Tanaka H, Ohshima T (2017), Zebrafish Mecp2 is required for proper axonal elongation of motor neurons and synapse formation. Developmental neurobiology 77:1101-1113.

O'Rawe JA, Wu Y, Dörfel MJ, Rope AF, Au PYB, Parboosingh JS, Moon S, Kousi M, et al. (2015), TAF1 variants are associated with dysmorphic features, intellectual disability, and neurological manifestations. The American Journal of Human Genetics 97:922-932.

O'Tuathaigh CMP, Babovic D, O'Meara G, Clifford JJ, Croke DT, Waddington JL (2007), Susceptibility genes for schizophrenia: characterisation of mutant mouse models at the level of phenotypic behaviour. Neuroscience \& Biobehavioral Reviews 31:60-78.

Owen MJ, Williams HJ, O'Donovan MCJCoig, development (2009), Schizophrenia genetics: advancing on two fronts. 19:266-270.

Panula P, Sallinen V, Sundvik M, Kolehmainen J, Torkko V, Tiittula A, Moshnyakov M, Podlasz PJZ (2006), Modulatory neurotransmitter systems and behavior: towards zebrafish models of neurodegenerative diseases. 3:235-247.

Papan C, Campos-Ortega JAJRsaodb (1994), On the formation of the neural keel and neural tube in the zebrafishDanio (Brachydanio) rerio. 203:178-186.

Parker MO, Brock AJ, Sudwarts A, Brennan CH (2014), Atomoxetine reduces anticipatory responding in a 5-choice serial reaction time task for adult zebrafish. Psychopharmacology 231:2671-2679.

Parker MO, Ife D, Ma J, Pancholi M, Smeraldi F, Straw C, Brennan CH (2013), Development and automation of a test of impulse control in zebrafish. Frontiers in systems neuroscience 7:65-65.

Perathoner S, Cordero-Maldonado ML, Crawford AD (2016), Potential of zebrafish as a model for exploring the role of the amygdala in emotional memory and motivational behavior. Journal of Neuroscience Research 94:445-462.

Pessah IN, Seegal RF, Lein PJ, LaSalle J, Yee BK, Van De Water J, Berman RFJN (2008), Immunologic and neurodevelopmental susceptibilities of autism. 29:532-545.

Piato AL, Rosemberg DB, Capiotti KM, Siebel AM, Herrmann AP, Ghisleni G, Vianna MR, Bogo MR, et al. (2011), Acute restraint stress in zebrafish: behavioral parameters and purinergic signaling. 36:1876.

Pietri T, Roman A-C, Guyon N, Romano SA, Washbourne P, Moens CB, De Polavieja GG, Sumbre G (2013), The first mecp2-null zebrafish model shows altered motor behaviors. Frontiers in neural circuits 7:118. Quiñonez-Silvero C, Hübner K, Herzog WJDB (2019), Development of the brain vasculature and the blood-brain barrier in zebrafish.

Rico EP, de Oliveira DL, Rosemberg DB, Mussulini BH, Bonan CD, Dias RD, Wofchuk S, Souza DO, et al. (2010), Expression and functional analysis of $\mathrm{Na+-dependent} \mathrm{glutamate} \mathrm{transporters} \mathrm{from} \mathrm{zebrafish}$ brain. 81:517-523.

Rihel J, Schier AFJDn (2012), Behavioral screening for neuroactive drugs in zebrafish. 72:373-385.

Rossignol DA, Genuis SJ, Frye RJTp (2014), Environmental toxicants and autism spectrum disorders: a systematic review. 4:e360.

Roy B, Ali DWJN (2014), Multiple types of GABAA responses identified from zebrafish Mauthner cells. 25:1232-1236.

Saili KS, Corvi MM, Weber DN, Patel AU, Das SR, Przybyla J, Anderson KA, Tanguay RLT (2012), Neurodevelopmental low-dose bisphenol A exposure leads to early life-stage hyperactivity and learning deficits in adult zebrafish. 291:83-92.

Sakai C, ljaz S, Hoffman EJ (2018), Zebrafish Models of Neurodevelopmental Disorders: Past, Present, and Future. 11.

Schalock RL, Luckasson RA, Shogren KA (2007), The renaming of mental retardation: Understanding the change to the term intellectual disability. Intellectual and developmental disabilities 45:116-124.

Schilling TFJZ (2002), The morphology of larval and adult zebrafish. 10:59-94.

Seibt KJ, Oliveira RdL, Zimmermann FF, Capiotti KM, Bogo MR, Ghisleni G, Bonan CD (2010), Antipsychotic drugs prevent the motor hyperactivity induced by psychotomimetic MK-801 in zebrafish (Danio rerio). Behavioural Brain Research 214:417-422. 
Seibt KJ, Piato AL, da Luz Oliveira R, Capiotti KM, Vianna MR, Bonan CD (2011), Antipsychotic drugs reverse MK-801-induced cognitive and social interaction deficits in zebrafish (Danio rerio). Behavioural Brain Research 224:135-139.

Seibt KJ, Piato AL, da Luz Oliveira R, Capiotti KM, Vianna MR, Bonan CDJBbr (2011), Antipsychotic drugs reverse MK-801-induced cognitive and social interaction deficits in zebrafish (Danio rerio). 224:135-139. Shevell MI, Ashwal S, Donley D, Flint J, Gingold M, Hirtz D, Majnemer A, Noetzel M, et al. (2003), Practice parameter: evaluation of the child with global developmental delay: report of the Quality Standards Subcommittee of the American Academy of Neurology and The Practice Committee of the Child Neurology Society. Neurology 60:367-380.

Simonoff E, Jones CR, Baird G, Pickles A, Happé F, Charman TJJoCP, Psychiatry (2013), The persistence and stability of psychiatric problems in adolescents with autism spectrum disorders. 54:186-194.

Singleman C, Holtzman NGJZ (2014), Growth and maturation in the zebrafish, Danio rerio: a staging tool for teaching and research. 11:396-406.

Souza BR, Tropepe VJRitn (2011), The role of dopaminergic signalling during larval zebrafish brain development: a tool for investigating the developmental basis of neuropsychiatric disorders. 22:107119.

Stankiewicz P, Khan TN, Szafranski P, Slattery L, Streff H, Vetrini F, Bernstein JA, Brown CW, et al. (2017), Haploinsufficiency of the chromatin remodeler BPTF causes syndromic developmental and speech delay, postnatal microcephaly, and dysmorphic features. The American Journal of Human Genetics 101:503-515.

Stewart AM, Nguyen M, Wong K, Poudel MK, Kalueff AVJPiN-P, Psychiatry B (2014), Developing zebrafish models of autism spectrum disorder (ASD). 50:27-36.

Strauss KA, Puffenberger EG, Huentelman MJ, Gottlieb S, Dobrin SE, Parod JM, Stephan DA, Morton DHJNEJoM (2006), Recessive symptomatic focal epilepsy and mutant contactin-associated protein-like 2. 354:1370-1377.

Tavares B, Lopes SSJAmp (2013), The importance of Zebrafish in biomedical research. 26:583-592.

Teles MC, Cardoso SD, Oliveira RF (2016), Social Plasticity Relies on Different Neuroplasticity Mechanisms across the Brain Social Decision-Making Network in Zebrafish. Frontiers in Behavioral Neuroscience 10:16.

Thapar A, Cooper M, Eyre O, Langley KJJoCP, Psychiatry (2013), Practitioner review: what have we learnt about the causes of ADHD? 54:3-16.

Thapar A, Cooper M, Rutter MJTLP (2017), Neurodevelopmental disorders. 4:339-346.

Tropepe V, Sive HLJG, Brain, Behavior (2003), Can zebrafish be used as a model to study the neurodevelopmental causes of autism? 2:268-281.

Van Laarhoven PM, Neitzel LR, Quintana AM, Geiger EA, Zackai EH, Clouthier DE, Artinger KB, Ming JE, et al. (2015), Kabuki syndrome genes KMT2D and KDM6A: functional analyses demonstrate critical roles in craniofacial, heart and brain development. Human molecular genetics 24:4443-4453.

Vaz R, Hofmeister W, Lindstrand A (2019), Zebrafish Models of Neurodevelopmental Disorders: Limitations and Benefits of Current Tools and Techniques. Int J Mol Sci 20.

Vitale W (2012), The Glutamate Hypothesis of Schizophrenia: Assessment of a Novel Antipsychotic in Zebrafish Larvae.

Wan J, Yourshaw M, Mamsa H, Rudnik-Schöneborn S, Menezes MP, Hong JE, Leong DW, Senderek J, et al. (2012), Mutations in the RNA exosome component gene EXOSC3 cause pontocerebellar hypoplasia and spinal motor neuron degeneration. Nature genetics 44:704.

Wang L, Jiang W, Lin Q, Zhang Y, Zhao C (2016), DNA methylation regulates gabrb2 mRNA expression: developmental variations and disruptions in I-methionine-induced zebrafish with schizophrenia-like symptoms. Genes, Brain and Behavior 15:702-710.

Wang S, Ji D, Yang Q, Li M, Ma Z, Zhang S, Li HJJoCP (2018), NEFLb impairs early nervous system development via regulation of neuron apoptosis in zebrafish.

Wang T, Liu Y, Liu H, Li C, Wang Y (2018), Auriculasin from Flemingia philippinensis roots shows good therapeutic indexes on hyperactive behavior in zebrafish. Biochemical and biophysical research communications 503:1254-1259.

Watemberg N, Silver S, Harel S, Lerman-Sagie TJJocn (2002), Significance of microcephaly among children with developmental disabilities. 17:117-122.

Winstanley CA, Eagle DM, Robbins TW (2006), Behavioral models of impulsivity in relation to ADHD: Translation between clinical and preclinical studies. Clinical Psychology Review 26:379-395. 
Woods CGJCoin (2004), Human microcephaly. 14:112-117.

Yamamoto K, Ruuskanen JO, Wullimann MF, Vernier PJM, Neuroscience C (2010), Two tyrosine hydroxylase genes in vertebrates: new dopaminergic territories revealed in the zebrafish brain. 43:394402.

Ye BS, Leung AOW, Wong MHJEp (2017), The association of environmental toxicants and autism spectrum disorders in children. 227:234-242.

Young S, González RA, Mullens H, Mutch L, Malet-Lambert I, Gudjonsson GHJPr (2018), Neurodevelopmental disorders in prison inmates: comorbidity and combined associations with psychiatric symptoms and behavioural disturbance. 261:109-115.

Zabegalov KN, Kolesnikova TO, Khatsko SL, Volgin AD, Yakovlev OA, Amstislavskaya TG, Friend AJ, Bao W, et al. (2019), Understanding zebrafish aggressive behavior. Behav Processes 158:200-210.

Zeiss CJ, Johnson LK (2017), Bridging the Gap between Reproducibility and Translation: Data Resources and Approaches. ILAR Journal 58:1-3.

Zeiss CJJlj (2017), From reproducibility to translation in neurodegenerative disease. 58:106-114.

Zimmermann FF, Gaspary KV, Siebel AM, Bonan CDJBbr (2016), Oxytocin reversed MK-801-induced social interaction and aggression deficits in zebrafish. 311:368-374.

Zimmermann FF, Gaspary KV, Siebel AM, Leite CE, Kist LW, Bogo MR, Bonan CDJMn (2017), Analysis of extracellular nucleotide metabolism in adult zebrafish after embryological exposure to valproic acid. 54:3542-3553. 